\title{
INFLUÊNCIA DA FORMAÇÃO DOCENTE NO PERFIL DO EGRESSO DE GRADUAÇÃO EM ENFERMAGEM
}

Ana Paula Dias França Guareschi ${ }^{1}$, Paulina Kurcgant ${ }^{2}$

\begin{abstract}
RESUMO: Este estudo objetiva conhecer pesquisas realizadas na área de enfermagem, que abordam a formação do enfermeiro docente como elemento que influencia a construção do perfil do egresso de enfermagem. O método adotado foi a revisão integrativa, no período de 2007 a 2012, nas bases de dados LILACS e Dedalus e na base de texto SciELO. Foram encontrados 24 artigos e analisados 14 por estarem de acordo com os critérios de inclusão do estudo. A partir dos perfis dos egressos de enfermagem prevalentes nos artigos, a análise temática propiciou a elaboração das categorias: Ser educador na perspectiva humanística; Ser educador na construção da dimensão crítico/reflexiva e Ser educador com responsabilidade social. Nos artigos é evidenciada a necessidade de se refletir sobre a formação do docente de enfermagem, as características essenciais deste profissional e a influência que esta formação pode ter na proposição do perfil do egresso de enfermagem. DESCRITORES: Docente de enfermagem; Educação em enfermagem; Educação superior.
\end{abstract}

\section{INFLUENCIA DE LA FORMACIÓN DOCENTE EN EL PERFIL DEL EGRESO DE GRADUACIÓN EN ENFERMERÍA}

RESUMEN: Este estudio objetiva conocer investigaciones realizadas en el área de enfermería, que abordan la formación del enfermero docente como elemento que tiene influencia en la construcción del perfil del egreso de enfermería. El método adoptado fue la revisión integrativa, en el periodo de 2007 a 2012, en las bases de datos LILACS y Dedalus y en la base de texto SciELO. Fueron encontrados 24 artículos y analizados 14 ya que estos estaban de acuerdo con los criterios de inclusión del estudio. Con base en los perfiles de los egresos de enfermería prevalentes en los artículos, el análisis temático posibilitó la elaboración de las categorías: Ser educador en la perspectiva humanística; Ser educador en la construcción de la dimensión crítico/reflexiva y Ser educador con responsabilidad social. En los artículos es evidenciada la necesidad de reflexionar acerca de la formación del docente de enfermería, las características esenciales de este profesional y la influencia que esta formación puede tener en la proposición del perfil del egreso de enfermería.

DESCRIPTORES: Docente de enfermería; Educación en enfermería; Educación superior.

\section{INFLUENCE OF LECTURER TRAINING ON THE PROFILE OF THE GRADUATE OF THE UNDERGRADUATE COURSE IN NURSING}

\begin{abstract}
This study aims to investigate research undertaken in the area of nursing, which addresses the training of the nurse lecturer as an element which influences the construction of the profile of the nursing graduate. The method adopted was the integrative review, in the period 2007-2012, in the LILACS and Dedalus databases and in the SciELO text base. 24 articles were found, of which 14 were analyzed, meeting the study's inclusion criteria. Based on the profiles of the graduates of undergraduate nursing courses prevalent in the articles, the thematic analysis allowed the elaboration of the categories: Being an educator in the humanistic perspective; Being an educator in the construction of the critical/reflexive dimension and Being an educator with social responsibility. The articles evidence the need to reflect on the training of the nursing lecturer, this professional's essential characteristics and the influence which this training may have on the proposition of the profile of the nursing graduate. DESCRIPTORS: Nursing lecturer; Education in nursing; Education, higher.
\end{abstract}

\footnotetext{
${ }^{1}$ Enfermeira. Mestre em Enfermagem. Doutoranda em Ciências.Universidade de São Paulo. Professora do Centro Universitário São Camilo. São Paulo-SP-Brasil

${ }^{2}$ Enfermeira. Doutora em Enfermagem. Professora da Universidade de São Paulo. São Paulo-SP-Brasil
}

Autor correspondente:

Recebido: 07/05/2013

Ana Paula Dias França Guareschi

Aprovado: 29/10/2013

Universidade de São Paulo

Av. Nazaré, 1501 - 04263-200 - São Paulo-SP-Brasil

E-mail: guaresch@uol.com.br 


\section{INTRODUÇÃO}

No Brasil, os cursos superiores e, posteriormente, as faculdades criadas e instaladas no país, voltavam-se à formação de profissionais para exercerem determinada profissão. Com estes pressupostos, os conhecimentos e experiências eram transmitidos de um professor que sabia e conhecia, para um aluno que não sabia e não conhecia, seguido de uma avaliação, que determinava se o discente estava apto, ou não, para exercer a profissão. Por outro lado, até a década de 1970, os professores eram escolhidos pela competência técnica, pois se acreditava que quem sabia exercer determinada profissão, automaticamente, sabia ensinar ${ }^{(1)}$. O professor tinha um papel centralizador, sendo a aprendizagem exclusivamente de sua responsabilidade e a "educação bancária" tornou-se forte até o século $\mathrm{XX}^{(2)}$.

No início da década de 1990, surgiram teorias que tratavam da formação docente. Estas teorias, descritas por Tardif e Nóvoa, forneceram elementos teórico-conceituais e metodológicos de investigação procurando captar o que os professores faziam, como pensavam, no que acreditavam, como se relacionavam com o trabalho, quais suas histórias de vida e que aspectos contribuíam para sua constituição profissional $^{(3)}$. No final do século XX, com o avanço nas áreas da Psicologia e da Educação, e com a ampliação do conhecimento sobre a formação docente, foi abandonado o modelo de educador centralizador, surgindo um novo perfil de educador, responsável pela formação de novos profissionais, participantes ativos de uma sociedade democrática na busca constante de desenvolvimento pessoal ${ }^{(2)}$.

Esta nova perspectiva no ensino superior foi contemplada na Lei de Diretrizes e Bases da Educação (LDB) n. 9.394, de 20 de dezembro de 1996, no artigo 43, nos incisos I, II, III, V e VI que descrevem a finalidade da Educação Superior. Esta finalidade determina o estímulo à criatividade e ao desenvolvimento do espírito científico e do pensamento reflexivo; à formação de diplomados aptos para a inserção em setores profissionais e ao desenvolvimento da sociedade brasileira colaborando com a formação contínua, estimulando o conhecimento dos problemas do mundo presente para a prestação de serviços especializados à comunidade e estabelecendo, com esta, uma relação de reciprocidade ${ }^{(4)}$.

A partir destas prerrogativas da LDB sobre a Educação Superior, fica explicitada a necessidade dos professores de se conscientizarem de que a docência exige capacitação específica, que pode ser adquirida individualmente ou com os pares. Com este novo paradigma de educador e de egresso do ensino superior teve início um conjunto de reformas nas políticas educacionais brasileiras que trouxeram, à discussão, novas propostas curriculares. Atualmente, os debates e as ações sobre este tema foram modificados ao instituírem o currículo nacional segundo parâmetros e diretrizes curriculares e processos de avaliação centralizados em resultados ${ }^{(5)}$.

Diante deste cenário, a universidade deverá ter como papel viabilizar a formação pedagógica dos docentes que ingressam na instituição superior, "estimulando e propiciando condições para que os professores se preparem para o exercício do magistério"(6:190).

Com relação à formação e preparação do professor universitário para o exercício do ensino, estudo sustenta a escassa atenção dada a este segmento ${ }^{(1)}$. Esta preocupação, embora presente nos cursos de Enfermagem e nas pesquisas sobre esta temática é menos considerada se comparada às relacionadas à prática do cuidado. Estudo discute a formação do docente de enfermagem ressaltando a importância da sua capacitação teórica, pedagógica e prática no contexto sócio econômico político e cultural da sociedade $^{(7)}$.

$\mathrm{Na}$ busca da qualidade na formação dos futuros enfermeiros torna-se necessário compreender as mudanças ocorridas no panorama educacional brasileiro, resgatando investigações na área de enfermagem que abordem a formação do enfermeiro docente, identificando, nestes estudos, elementos que contribuem para a construção do perfil do egresso de enfermagem proposto pela Resolução 3/2001 do Conselho Nacional de Educação/ Câmera de Educação Superior.

\section{MÉTODO}

Para o desenvolvimento deste estudo adotou-se o método da revisão integrativa da literatura de acordo com as seguintes etapas: formulação do problema, busca na literatura, avaliação e análise dos dados e apresentação dos resultados ${ }^{(8)}$.

A etapa de formulação do problema incluiu o interesse do estudo, o propósito da revisão integrativa e a elaboração da questão norteadora. Assim, segundo o problema de interesse, foi elaborada a seguinte questão norteadora que direcionou a busca: 
"Quais são as investigações na área de enfermagem que abordam a formação do enfermeiro docente e descrevem a sua influência na construção do perfil do egresso de enfermagem?"

Como critérios de inclusão dos artigos foram considerados: artigos de pesquisa com texto completo, disponíveis eletronicamente nas bases de dados, nos idiomas inglês, espanhol ou português, publicados no período de 2007 a dezembro de 2012 (período da coleta dos dados); produções que contemplam a formação do enfermeiro docente no ensino superior; enfermeiros docentes como participantes da pesquisa e desenho metodológico qualitativo ou quantitativo. Quanto aos critérios de exclusão, foram consideradas as publicações do tipo editorial, de revisão narrativa ou sistemática, resumo em Anais de evento, dissertações e teses, bem como publicações repetidas.

A seleção dos artigos foi feita nas bases de dados Literatura Latino-Americana e do Caribe em Ciências da Saúde (LILACS), Dedalus e base textual Scientific Electronic Library Online (SciELO).

A busca foi realizada mediante a identificação dos descritores com base nos Descritores em Ciências da Saúde (DeCS), considerando-se os termos presentes na pergunta norteadora. Assim, identificaram-se os descritores: "Docente de Enfermagem"; "Educação em Enfermagem" e "Ensino Superior", ressaltando, que para todas as bases, utilizou-se o cruzamento dos descritores.

Os artigos identificados foram submetidos a duas etapas de avaliação. A primeira constou da apreciação do título e do resumo, objetivando identificar sua adequação à pergunta norteadora e aos critérios de inclusão e exclusão pré-estabelecidos. A segunda etapa considerou as características metodológicas relevantes, por meio de instrumento adaptado, contemplando: o tipo de estudo; os autores; os objetivos; os resultados e as conclusões ${ }^{(8)}$.

$\mathrm{Na}$ primeira busca foram identificados 250 artigos científicos. Após a primeira etapa de avaliação houve adequação de 24 artigos científicos, oito encontrados na base de texto SciELO, 10 nas bases de dados LILACS e um na Dedalus. Foram encontrados, em mais de uma base de dados, cinco artigos. Na segunda etapa de avaliação, após a leitura dos 24 artigos na íntegra, foram selecionados, para a presente pesquisa, 14 artigos.

Como Categoria Analítica para a análise dos achados resgatados nos artigos selecionados, no referente ao perfil do enfermeiro egresso, foi adotado o perfil do egresso de enfermagem descrito no Artigo $3^{\circ}$ da Resolução 3/2001 do (CNE/ CES), que propõe um enfermeiro, com formação generalista, humanista, crítica e reflexiva. Este enfermeiro deverá ser capaz de conhecer e intervir sobre os problemas/situações de saúde doença prevalentes no perfil epidemiológico nacional, com ênfase na sua região de atuação, identificando as dimensões biopsicossociais e seus determinantes. $\mathrm{O}$ enfermeiro deve estar capacitado a atuar com senso de responsabilidade social e compromisso com a cidadania e como promotor da saúde integral do ser humano ${ }^{(9)}$. Para a análise dos conteúdos resgatados nos artigos, e consequente construção das Categorias Empíricas, foi adotada a Análise Temática ${ }^{(10)}$.

Assim, os artigos foram analisados quanto ao ano de publicação, delineamento da pesquisa, objeto do estudo e quanto aos achados referentes à formação do enfermeiro/docente e o perfil do egresso CNE/ CES.

\section{RESULTADOS}

Foram identificados nos resultados, os perfis do egresso generalista (2), autônomo (4) e capaz de conhecer os problemas/situações de saúde (5), os de maior prevalência: humanista (9), crítico/reflexivo (8) e de responsabilidade social (7), estão representados nos Quadros 1, 2 e 3.

As revistas que mais publicaram artigos sobre a temática deste estudo foram: Revista Brasileira de Enfermagem (4); Revista da Escola de Enfermagem da USP (3) e Revista Latino-Americana de Enfermagem (3). O período de maior publicação foi em 2011, 2009, 2007 com três artigos em cada ano.

Com relação ao delineamento da pesquisa 14 artigos adotaram metodologias qualitativas, sendo fenomenologia (5) e estudo exploratório descritivointerpretativo (5) o tipo de pesquisa mais empregado. Em quatro não foi definido o tipo de estudo.

Um aspecto consensual nos estudos analisados refere-se à importância do enfermeiro docente adquirir a capacitação pedagógica para exercer o papel de educador no ensino superior. Outros aspectos evidenciados são a necessidade da educação permanente para este profissional e a influência da formação do docente de enfermagem na construção do perfil dos futuros enfermeiros. 
Quadro 1 - Títulos das publicações científicas sobre formação do docente de enfermagem e a contribuição para o perfil humanístico do egresso de Enfermagem entre 2007 e 2012. São Paulo-SP-Brasil, 2013

\begin{tabular}{|l|c|}
\hline Elementos da formação docente correlacionados com o perfil de egressos & Referência \\
\hline $\begin{array}{l}\text { O docente tem papel de facilitador na construção da visão humanística do egresso, utilizando a } \\
\text { abordagem holística, no processo de formação do enfermeiro. }\end{array}$ & 7 \\
\hline $\begin{array}{l}\text { O docente está buscando outras maneiras de ensinar e aprender a fazer Enfermagem que sejam } \\
\text { fundamentadas na solidariedade, responsabilidade e sensibilidade, pois é ele quem ensina e } \\
\text { aprende com o discente a cuidar de outro ser humano. }\end{array}$ & 11 \\
\hline $\begin{array}{l}\text { O ser-docente-enfermeiro necessita restaurar a sensibilidade, por meio do diálogo com o outro } \\
\text { para ensinar e aprender a ser e fazer Enfermagem. }\end{array}$ & 12 \\
\hline $\begin{array}{l}\text { Os esforços do professor destinam-se ao envolvimento do futuro profissional de enfermagem } \\
\text { com o cuidar e com o aprender. }\end{array}$ & 13 \\
\hline $\begin{array}{l}\text { O docente além do saber, necessita de habilidades adquiridas na sua trajetória enquanto ser, que } \\
\text { serão aplicadas em ambiente complexo, como o clínico, que contempla o relacionamento com o } \\
\text { paciente, estudante, enfermeira clínica e equipe de saúde. }\end{array}$ & 14 \\
\hline $\begin{array}{l}\text { Contextualizar é estratégia fundamental para encontrar sentidos para o cuidado humano. } \\
\text { O docente tem papel de facilitador na construção da visão humanística do egresso, utilizando a } \\
\text { abordagem holística, no processo de formação do enfermeiro. }\end{array}$ & 16 \\
\hline $\begin{array}{l}\text { Responsabilidade na formação moral do profissional. } \\
\text { Ensinar conteúdos atitudinais depende da capacitação pedagógica do docente e a falta deste } \\
\text { preparo dificulta a compreensão do que deve ser ensinado aos alunos. Manter uma conversa } \\
\text { aberta, com maior aproximação com o aluno e criar oportunidades que possibilitam ao aluno } \\
\text { expressar suas dúvidas e sentimentos. }\end{array}$ & 19 \\
\hline
\end{tabular}

Quadro 2 - Títulos das publicações científicas sobre formação do docente de enfermagem e a contribuição para o perfil crítico/reflexivo do egresso de Enfermagem entre 2007 e 2012. São Paulo-SP-Brasil, 2013

\begin{tabular}{|l|c|}
\hline Elementos da formação docente correlacionados com o perfil de egressos & Referência \\
\hline $\begin{array}{l}\text { Para o enfermeiro ser crítico e reflexivo, é fundamental que o docente esteja capacitado pedago- } \\
\text { gicamente, para auxiliar na construção do perfil do futuro enfermeiro. }\end{array}$ & 7 \\
\hline $\begin{array}{l}\text { Transformar os espaços de aprendizagem em experiências significativas para os estudantes, a } \\
\text { partir da sua própria realidade, instigando a capacidade de perceberem a sensibilidade, a intuição, } \\
\text { a imaginação e a criatividade. }\end{array}$ & 12 \\
\hline $\begin{array}{l}\text { Ao professor de enfermagem, compete a tarefa de confrontar a informação e sua relação com } \\
\text { a realidade, capacitar e permitir que o estudante apreenda, atribua ou reconstrua a relevância } \\
\text { deste conteúdo. }\end{array}$ & 13 \\
\hline $\begin{array}{l}\text { Estimular a criatividade e a curiosidade como estratégia de ensino-aprendizagem. } \\
\text { A omissão de docentes por deficiência na sua formação, pode representar danos irreparáveis aos } \\
\text { futuros profissionais, ou seja, aqueles que atuarem de forma alienada, dificilmente, irão despertar } \\
\text { a formação crítica do egresso. }\end{array}$ & 16 \\
\hline $\begin{array}{l}\text { Cabe ao docente repensar a educação como ato político, almejar a práxis criativa na formação } \\
\text { do perfil do enfermeiro para atuar como massa crítica. }\end{array}$ & 20 \\
\hline $\begin{array}{l}\text { Utilização da teoria de Paulo Freire permitindo base crítica reflexiva e participativa do docente } \\
\text { e estimulando o protagonismo do aluno. }\end{array}$ & 21 \\
\hline
\end{tabular}


Quadro 3 - Títulos das publicações científicas sobre formação do docente de enfermagem e a contribuição para o perfil de responsabilidade social do egresso de Enfermagem entre 2007 e 2012. São Paulo-SP-Brasil, 2013

\begin{tabular}{|l|c|}
\hline Elementos da formação docente correlacionados com o perfil de egressos & Referência \\
\hline $\begin{array}{l}\text { Para o enfermeiro ser transformador da sociedade, o docente deve estar capacitado para auxiliar } \\
\text { na construção do perfil do futuro enfermeiro. }\end{array}$ & 7 \\
\hline $\begin{array}{l}\text { Para os docentes, a finalidade de ensinar e aprender a ser e fazer Enfermagem, é formar seres } \\
\text { humanos de maneira que o outro possa confiar e respeitar a partir de sua consciência social e } \\
\text { possuir um comportamento ético. }\end{array}$ & 11 \\
\hline $\begin{array}{l}\text { Estar ao lado do aluno como professor, para que se possa constatar e transformar a realidade. } \\
\text { Viver o processo ensino-aprendizagem mediado pela transdisciplinaridade, proposta por Morin, } \\
\text { propiciará formação de cidadãos planetários, solidários e éticos, aptos a enfrentar os desafios atuais. }\end{array}$ & 15 \\
\hline $\begin{array}{l}\text { Responsabilidade na formação profissional, moral e científica dos egressos. } \\
\text { O professor é obrigado a assumir de forma competente a formação mais que técnica e científica, }, \\
\text { mas também ética para os futuros enfermeiros, voltada para a transformação social. }\end{array}$ & 18 \\
\hline $\begin{array}{l}\text { Espera-se que o docente universitário forme profissionais competentes e comprometidos social- } \\
\text { mente, para tanto, faz-se necessário ajudar os docentes na sua qualificação. }\end{array}$ & 23 \\
\hline $\begin{array}{l}\text { A formação do professor possibilita uma prática pedagógica atual, contextualizada, preocupada } \\
\text { com o contexto sócio-político-cultural com vistas às transformações da sociedade, procurando } \\
\text { assegurar a flexibilidade, a diversidade e a qualidade do ensino oferecido ao aluno. }\end{array}$ & 24 \\
\hline
\end{tabular}

\section{DISCUSSÃO}

Os dados resgatados nos artigos selecionados, analisados segundo o referencial da Categoria Analítica adotada no presente estudo, permitiram a construção das Categorias Empíricas a seguir apresentadas.

\section{Ser educador na perspectiva humanística}

A enfermagem é uma profissão que tem na sua essência o ser humano que traz uma história e reconhecido pelas suas intenções, ações e expressões no mundo. Com isso, o docente busca outras formas de ensinar e aprender a fazer Enfermagem, fundamentadas na solidariedade, responsabilidade e sensibilidade, ensinando e aprendendo com o discente a cuidar de outro ser humano ${ }^{(11)}$.

O docente contribui para o desenvolvimento das potencialidades do aluno, possibilitando o despertar da sensibilidade, propiciando espaços para a construção do saber objetivo sem negar a subjetividade, adotando o diálogo e a aproximação com o outro. Desta forma, o ensinar e o aprender a ser e fazer Enfermagem envolve intencionalidade e conhecimento como experiência vivida com o outro e como fonte de conhecimento fundamentado nos fenômenos compartilhados no cotidiano do cuidado ${ }^{(12)}$.

O professor de enfermagem tende a acreditar que o estudante, por meio da vivência do cuidar, é lançado ao mundo dos valores e das relações interpessoais. Ele pode também se tornar o conselheiro fiel, o amigo da jornada que alerta para os perigos dela advindos, ao tempo que os instiga a apreciar a paisagem, ajudando a desnudar suas peculiaridades e belezas ${ }^{(13: 728)}$.

Assim, o relacionamento do enfermeiro docente com o estudante não é de dominação, mas de convivência; não é somente de intervenção, mas de interação ${ }^{(14)}$. O docente, assim como o aluno, é um ser complexo, sendo a um só tempo biológico, psíquico, social, espiritual, assim como, o indivíduo que será cuidado pelo egresso/profissional ${ }^{(15)}$.

Humanizar o ensino, a partir dos relacionamentos criados no processo de formação, é uma proposta que será mais expressiva do que a de humanizar a assistência. O docente como facilitador na abordagem holística no processo de formação do enfermeiro tem papel fundamental na utilização de estratégias para o estabelecimento de relações humanizadas ${ }^{(16)}$.

O egresso/profissional precisa entender as concepções, percepções e valores que influenciam a saúde dos seus pacientes, rompendo com o modelo biomédico com práticas profissionais técnico-instrumentais, em detrimento das dimensões interpessoais que caracterizam o ato de cuidar. Para tanto, os docentes necessitam ter competência para compartilhar o conhecimento teórico com os alunos, em estreita relação no que se refere ao cuidado do paciente ${ }^{(17)}$. 
O ensino de enfermagem é realizado em um ambiente onde os fenômenos pedagógicos ocorrem por meio de uma relação complexa, na medida em que além do professor e aluno, existe a pessoa do paciente ${ }^{(18)}$. Neste contexto, o educador, além dos conhecimentos específicos da Enfermagem, deverá instrumentalizar os futuros profissionais no que se refere ao relacionamento interpessoal e à ética nas relações humanas.

O ensino e a avaliação atitudinal, que corroboram com a visão humanística do egresso/profissional, não são explicitados nos conteúdos programáticos das disciplinas ficando, a critério de cada docente, como abordá-la ${ }^{(19)}$.

Para tanto, o educador necessita de capacitação de como ensinar e avaliar temas atitudinais como respeito, postura, atitudes em relação ao trabalho e à instituição, conceitos relacionados ao valor e à justiça, afetividade terapêutica e identidade e ética do enfermeiro. Para que o docente seja um facilitador no processo de aprendizagem é necessário que a atitude docente seja coerente com o que está sendo proposto para que o estudante consiga compreender as estratégias pedagógicas com enfoque na aprendizagem atitudinal, pelo exemplo de vida profissional e aproximação do docente com o aluno através de uma conversa aberta ${ }^{(19)}$.

\section{Ser educadornaconstruçãodadimensãocrítico/reflexiva}

Segundo pressupostos da Teoria Libertadora de Paulo Freire cabe ao docente repensar a educação como ato político, almejar a práxis criativa na formação do perfil do enfermeiro para atuar com crítica, ter como objetivos libertar e estimular a autonomia do discente, a fim de que este seja capaz de refletir, criticamente, sobre seu próprio agir ${ }^{(19-20)}$.

A construção da consciência reflexiva é mais uma das atribuições do educador, pois ao despertar as potencialidades do aluno (consciência de poder), propiciará que o mesmo reconheça o valor do cuidado humano, presente em seu cotidiano ${ }^{(13)}$.

Ao professor de enfermagem compete ainda, a tarefa de confrontar a informação e sua relação com a realidade; ensinar os alunos a associarem e ligarem os saberes em uma trama única para dar sentido ao processo ensino-aprendizagem, e capacitar e permitir que o estudante apreenda, atribua ou reconstrua a relevância deste conteúdo através da sua capacidade de questionar, discutir, analisar e construir o conhecimento, com a valorização da percepção da sensibilidade, intuição, imaginação e criatividade ${ }^{(12-13,15,21)}$.

A preocupação com a formação do enfermeiro crítico, reflexivo e transformador da sociedade é bem recente, sendo que sua efetivação passa, obrigatoriamente, pela formação de professores capacitados para o desenvolvimento do pensamento reflexivo, no movimento dialético da ação-reflexão-ação. Neste sentido, a prática pedagógica do enfermeiro professor deve passar pelo processo reflexivo, capaz de modificar o contexto educacional do ensino de Enfermagem marcado pela transmissão de conteúdos, fragmentação do ensino e da dicotomia teoria-prática ${ }^{(7,21)}$.

\section{Ser educador com responsabilidade social}

Espera-se que o docente universitário forme profissionais competentes e comprometidos socialmente. Para tanto, há necessidade dos docentes qualificarem suas aptidões. Nesta perspectiva, para que o processo ensino aprendizagem cumpra este papel, deve ocorrer a capacitação, a qualificação e o desenvolvimento do corpo docente no que diz respeito à dimensão pedagógica, à perspectiva político-social e à pesquisa ${ }^{(22)}$.

Devem ser trabalhados conhecimentos que permitam ser revistos e que sejam úteis ao ser humano e à sociedade; que permitam desenvolver novas características nos professores e alunos, para que sejam capazes de enfrentar as adversidades do mundo atual ${ }^{(23)}$.

Ensinar a cidadania como processo de transformação da realidade é ensinar a dividir, a comunicar, a comungar com o outro, compreender o outro na sua especificidade e unidade, por meio do autoconhecimento, do exercício da autocrítica, dos sentimentos de solidariedade e de responsabilidade ${ }^{(15)}$.

A finalidade de ensinar e aprender a ser e fazer Enfermagem, para os docentes, é formar seres humanos com consciência social, moral científica e comportamento ético, permitindo o exercício da criatividade e do significado social da atividade ${ }^{(11,17-18,24)}$.

Uma das grandes responsabilidades dos professores é preparar os jovens, não só para um futuro confiante, mas para que construam de maneira determinada e responsável um mundo melhor ${ }^{(15)}$.

\section{CONCLUSÃO}

Nas pesquisas selecionadas foi evidente a coesão dos autores quanto à necessidade de se refletir sobre a formação do docente de enfermagem, sobre as características essenciais deste profissional e sobre a influência, que esta formação tem na proposição do perfil do egresso de enfermagem. 
O processo ensino aprendizagem do futuro enfermeiro precisa ser resignificado constantemente pelos docentes e pela instituição de ensino superior, para que o perfil do egresso de um profissional humanista, crítico, reflexivo e com responsabilidade social seja alcançado.

\section{REFERÊNCIAS}

1. Masseto MT, organizador. Docência na universidade. Campinas: Papirus; 1998.

2. Campos JT de. Paulo Freire e as novas tendências da educação. Revista e-curriculum. [Internet] 2007;3(1) [acesso em 1 jul 2013]. Disponível: http://revistas.pucsp. br/index.php/curriculum/article/view/3196/2118

3. Alves WF. A formação de professores e as teorias do saber docente: contextos, dúvidas e desafio. Educ. Pesqui. [Internet] 2007;33(2) [acesso em $6 \mathrm{fev}$ 2013]. Disponível: http://dx.doi.org/10.1590/S151797022007000200006

4. Brasil. Lei n. 9.393, de 20 de dezembro de 1996: estabelece as diretrizes e bases da educação nacional. Lei de Diretrizes e Bases da Educação - LDB. [Internet] 20 dez 1996 [acesso em 5 dez 2012]. Disponível: http:// www.planalto.gov.br/ccivil_03/Leis/L9394.htm

5. Lopes AC, Lopez SB. A performatividade nas políticas de currículo: o caso do ENEM. Educ. rev. [Internet] 2010;26(1) [acesso em 1 fev 2013]. Disponível: http:// dx.doi.org/10.1590/S0102-46982010000100005

6. Veiga IPA, Castanho MELM, organizadores. Pedagogia Universitária: a aula em foco. Campinas: Papirus; 2000.

7. Rodrigues MTP, Sobrino JACM. Enfermeiro professor: um diálogo com a formação pedagógica. Rev. bras. enferm. [Internet] 2007;60(4) [acesso em 10 fev 2013]. Disponível: http://www.redalyc.org/ pdf/2670/267020026021.pdf

8. Souza MT de, Silva MD da, Carvalho R. Revisão integrativa: o que é e como fazer. Einstein. [Internet] 2010;8(1) [acesso em 1 fev 2013]. Disponível: http://apps. einstein.br/revista/arquivos/PDF/1134-Einsteinv8n1_ p102-106_port.pdf

9. Ministério da Educação (BR). Conselho Nacional de Educação. Diretrizes Curriculares Nacionais do Curso de Graduação em Enfermagem. Resolução CNE/CES 3/2001. [Internet] 3 abr 2001 [acesso em 12 jan 2013]. Disponível: http://portal.mec.gov.br/cne/arquivos/pdf/ CES03.pdf
10. Minayo MC. O desafio do conhecimento: pesquisa qualitativa em saúde. 12a ed. São Paulo: Hucitec; 2010.

11. Terra MG, Gonçalves LHT, Santos EKA dos, Erdmann AL. O dito e o não-dito do ser-docente-enfermeiro/a na compreensão da sensibilidade. Rev. bras. enferm. [Internet] 2008;61(5) [acesso em 2 fev 2013]. Disponível: http://dx.doi.org/10.1590/S0034-71672008000500005

12. Terra MG, Gonçalves LHT, Santos EKA dos, Erdmann AL. Sensibilidade nas relações e interações entre ensinar e aprender a ser e fazer enfermagem. Rev. Latino-Am. Enfermagem. [Internet] 2010;18(2) [acesso em 2 fev 2013]. Disponível: http://dx.doi.org/10.1590/ S0104-11692010000200010

13. Carneiro AD, Costa SFGC, Marconi JPP. Disseminação de valores éticos no ensino do cuidar em Enfermagem: estudo fenomenológico. Texto Contexto. [Internet] 2009;18(4) [acesso em 18 fev 2013]. Disponível: http:// dx.doi.org/10.1590/S0104-07072009000400014

14. Bettancourt L, Muñoz LA, Merighi MAB, Santos MF. O docente de enfermagem nos campos de prática clínica: um enfoque fenomenológico. Rev. Latino-Am. Enfermagem. [Internet] 2011;19(5) [acesso em $18 \mathrm{fev}$ 2013]. Disponível: http://dx.doi.org/10.1590/S010411692011000500018

15. Silva AL, Camillo SO. A educação em enfermagem à luz do paradigma da complexidade. Rev Esc Enferm USP. [Internet] 2007;41(3) [acesso em $12 \mathrm{fev}$ 2013]. Disponível: http://dx.doi.org/10.1590/S008062342007000300009

16. Rodrigues J, Mantovani MF. O docente de enfermagem e sua representação sobre a formação profissional. Esc. Anna Nery. [Internet] 2007;11(3) [acesso em 15 fev 2013]. Disponível: http://dx.doi.org/10.1590/S141481452007000300015

17. Aguayo González M, Monereo Font C. The nurse teacher. Construction of a new professional identity. Invest. educ. enferm. [Internet] 2012;30(3) [acesso em 10 fev 2013]. Disponível: http://www.scielo.org.co/pdf/ iee/v30n3/v30n3a13.pdf

18. Ferreira EM, Fernandes MFP, Prado C, Baptista PCP, Freitas GFF, BoniniBB. Prazere sofrimento no processo de trabalho do enfermeiro docente. Rev Esc Enferm USP. [Internet] 2009;43(n. esp. 2) [acesso em 12 fev 2013]. Disponível: http://dx.doi.org/10.1590/S0080-62342009000600025

19. Leite MTS, Ohara CVS, Kakehashi TY, Ribeiro CA. Unidade teórico-prática na práxis de um currículo 
integrado: percepção de docentes de Enfermagem na saúde da criança e do adolescente. Rev. bras. enferm. [Internet] 2011;64(4) [acesso em $14 \mathrm{fev}$ 2013]. Disponível: http://dx.doi.org/10.1590/S003471672011000400014

20. Backes VMS, Moya JLM, Prado ML. Processo de construção do conhecimento pedagógico do docente universitário de enfermagem. Rev. Latino-Am. Enfermagem. [Internet] 2011;19(2) [acesso em $14 \mathrm{fev}$ 2013]. Disponível: http://dx.doi.org/10.1590/S010411692011000200026

21. Rodrigues MTP, Sobrinho JACM. Obstáculos didáticos no cotidiano da prática pedagógica do enfermeiro professor. Rev. bras. enferm. [Internet] 2008;61(4) [acesso em 15 fev 2013]. Disponível: http://dx.doi. org/10.1590/S0034-71672008000400006

22. Madeira MZA, Lima MGSB. O significado da prática docente na constituição do saber ensinar das professoras do Curso de Enfermagem da Universidade Federal do Piauí. Texto Contexto. [Internet] 2010;19(1) [acesso em 5 fev 2013]. Disponível: http://dx.doi.org/10.1590/ S0104-07072010000100008

23. Madeira MZA, Lima MGSB. A prática pedagógica das professoras de enfermagem e os saberes. Rev. bras. enferm. [Internet] 2007;60(4) [acesso em 5 fev 2013]. Disponível: http://dx.doi.org/10.1590/S003471672007000400008

24. Araújo JL, Jorge MSB, Freitas CHAF, Moreira TMM. O ensino da ética e da bioética no processo de formação do Enfermeiro frente às diretrizes curriculares nacionais. Cogitare enferm. [Internet] 2009;14(3) [acesso em 5 fev 2013]. Disponível: http://ojs.c3sl.ufpr.br/ojs2/index.php/ cogitare/article/view/16190/10708 